\title{
Power Generation Using Piezoelectric Material
}

\author{
Akshaya Hatey, Vaibhavi Koli, Priti Mishra, Devanand Bathe
}

Department of Electronics Engineering, KJ Somaiya Institute of Engineering and Information Technology Sion, Maharashtra, India

Article Info

Volume 7, Issue 4

Page Number : 131-134

Publication Issue :

July-August-2020

\section{Article History}

Accepted : 20 July 2020

Published : 30 July 2020

\section{ABSTRACT}

The energy crisis is the main issue of the world these days. The motto of the research work is to face the crisis. Nowadays the demand for electricity is increasing day by day, so the ultimate solution to solve this problem is to use renewable sources of energy. In this project, we are generating electricity using non-conventional techniques. In this project, when human walks surrounding, some force is applied on the surface of the piezo sheet, this force can be used to generate electricity. The piezoelectric crystal has crystalline structure \& ability to convert mechanical stress into electrical energy.

Keywords : Piezo plate, Battery, Arduino, LED, Inverter, Rectifier

\section{INTRODUCTION}

The main principle of this project is the piezoelectric effect shown by metals. When person walks he puts some pressure or weight on the floor. The energy generating floor uses this to generate electricity for bending the piezoelectric material. This project not only provides an efficient source of energy but also a clean and pollution free environment. The main advantage of this project is that it is cheap \& easy in installation Power generated by the human pressure is stored and used for many applications.

In engineering or household application, current is often described as being either direct current or alternating current. This term refers to how the current varies in time. direct current, as produced by example from a battery and require by most electronic devices, is a unidirectional flow from the positive part of the circuit to the negative part. If, as is most common, this flow is carried by electrons, they will be travelling in the opposite direction. Ac current is any current that reverses direction repeatedly, almost always this take the form of a sine waves.

\section{WORKING PRINCIPLE}

The key principle behind the energy generating floor is the piezoelectric effect shown by metals. When a person walks he puts some pressure on the floor due to his weight and muscle power. The Electricity generating Floor uses this force to generate electricity by utilizing this force for bending the piezoelectric material. 


\section{WORKING}

\section{A. System Details}

1. Piezoelectric Crystal: piezoelectricity is the electric charge that accumulates in certain solid material in response to applied mechanical stress. Applying mechanical energy to a crystal called a direct piezoelectric effect. a piezoelectric crystal is placed between two metal plates. The metal plates collect these charges which can be used to produce a voltage \& send an electrical current through circuit.

2. Voltage Divider : In electronics, a voltage divider (also known as a potential divider) is a passive linear circuit that produces an output voltage $\left(\mathrm{V}_{\text {out }}\right)$ that is a fraction of its input voltage $\left(V_{\text {in }}\right)$. Voltage division is the result of distributing the input voltage among the components of the divider. A simple example of a voltage divider is two resistors connected in series, with the input voltage applied across the resistor pair and the output voltage emerging from the connection between them.

3. Rectifier and filter: Rectifier and filter circuit is to filter out the output of piezo. Bridge rectifier is an Alternating Current (AC) to Direct Current (DC) converter that rectifies mains $A C$ input to $D C$ output. They can be constructed with four or more diodes or any other controlled solid-state switches.

4. Battery: The battery is connected to the inverter. This inverter is used to convert the 12-volt D.C to the 230 volt A.C. This 230 volt A.C voltage is used to activate the loads.

5. Clt Sensor : Cross-laminated timber (CLT) is a wood panel product made from gluing together layers of solid-sawn lumber. Regular timber is basically an anisotropic material means that the physical properties change depending on the direction at which the force is applied. But by gluing layers of wood at right angles, the panel is able to achieve better structural rigidity in both directions. It is similar to plywood but with distinctively thicker laminations

6. LCD Screen : A liquid-crystal display (LCD) is a flat panel which uses the light-modulatin properties of liquid crystals combined with polarizers. . LCDs are available to display arbitrary or fixed images with low information content, which can be displayed or hidden, such as preset words, digits, and seven-segment displays, as in a digital clock.

7. LED Display : A LED display is a flat panel display that uses an array of light-emitting diodes as pixels for a video display. LED displays can offer higher contrast ratios than a projector and are thus an alternative to traditional projection screens.

B. Block Diagram

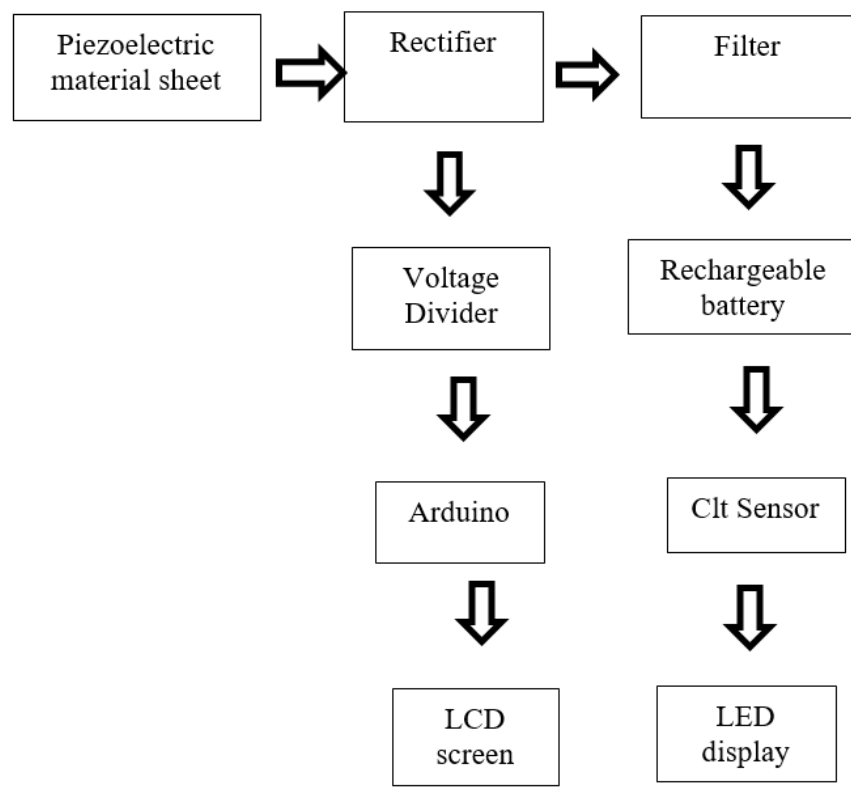

Fig 1. 
C. Implementation

1. The aim of this project is to generate electricity using footstep. The output of the piezo is AC in nature.

2. When a person puts pressure on the piezo sheet floor the output which is produced by the piezo sheet is given to the rectifier and filter connection suing rectifier IC W10 50V 1.5A .

3. Voltage obtained by the rectifier filter connection can be further sent to the voltage divider circuit. It will sample the voltage successfully.

4. This sample output voltage given to the arduino pin which is connected to the LCD display.

5. At the output when we put the pressure on the piezo crystal it will generate the voltage upto $12 \mathrm{~V}$.

6. The sensor is connected to measure the flow of current through DC load.

7. 10 piezos are connected in series parallel manner.

8. The arrangement of piezo crystal is placed on a hard wooden plank to protect the sheet from physical damage.

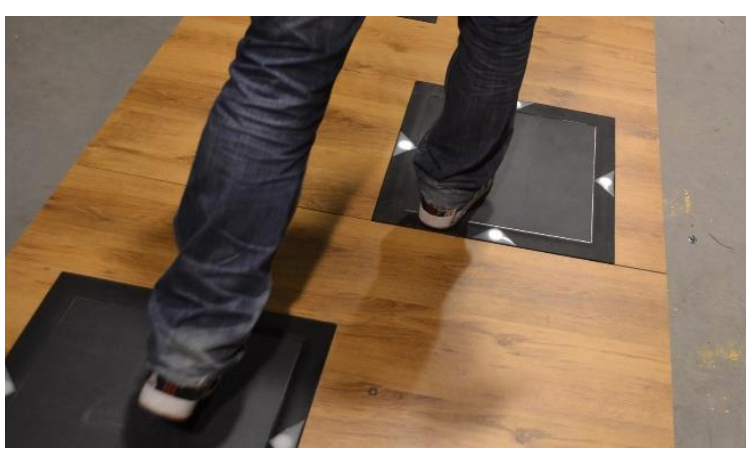

Fig.2

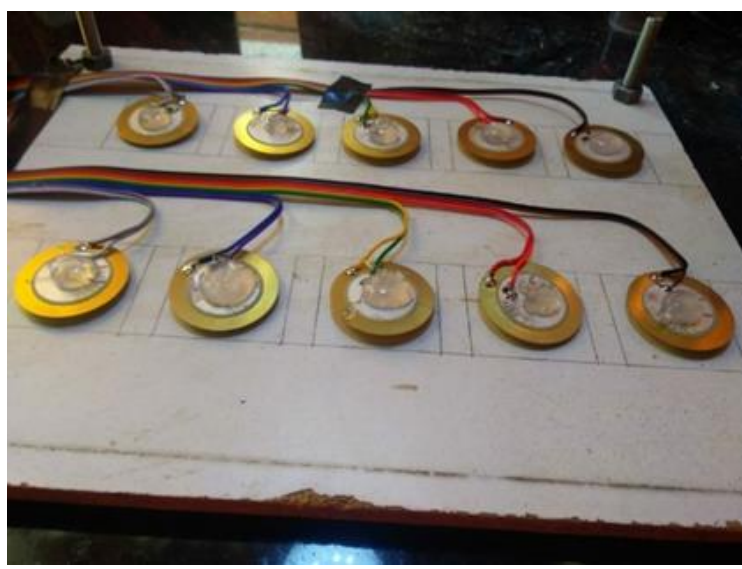

Fig.3

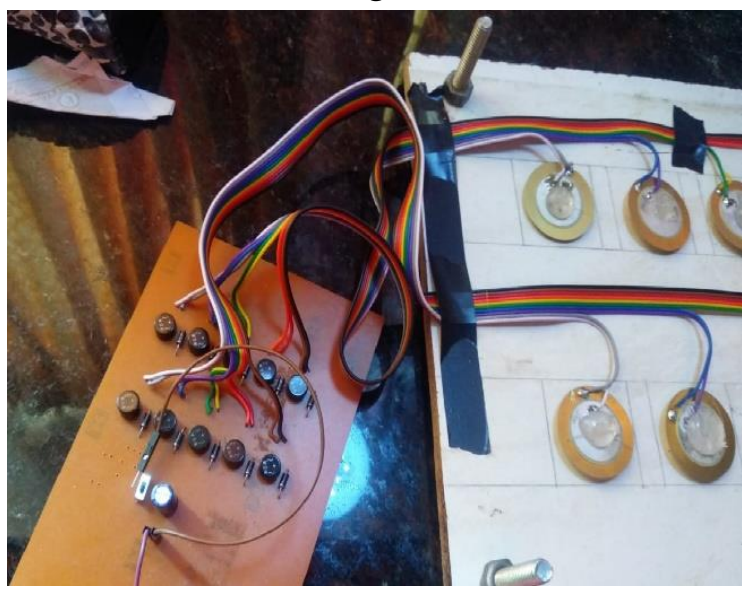

Fig.3

\section{EXPECTED RESULT}

When we applied pressure on the piezoelectric sensor the voltage deflection is sensed. i.e when we apply pressure and realesed it then the LCD display shows the deflection. This deflection depends upon the applied pressure and the type of piezoelectric material we used. As we connected 10 piezos in series parallel manner, we expected that it will genenrate the voltage upto $9 \mathrm{~V}$. the voltage generation is totally depends upon how much we applied pressure.

\section{CONCLUSION}

Here we are introducing a new source or way of generation of electricity. Running cost is negligible of the project because here no special fuel is required like other power generating stations. There is no pollution with this technology as compared to other 
power generating technologies, hence it is ecofriendly in nature. Untapped Mechanical energy associated with footsteps is used for generation of electricity. For more generation of electricity, more pressure is required hence the project can be successfully implemented in crowded areas.

\section{FUTURE SCOPE}

This project can be successfully implemented in airports, railway stations and the technology can be incorporated to generate power in the following applications

- Below railway tracks

- School/ college

- Staircases

- In car tires

- In boxing panel

\section{VII.REFERENCES}

[1]. Power generation using piezoelectric material Vikram Rathod, Shubhada Janotkar, Nikhil Daundkar,Ajay Mahajan,Anup Chaple (Feb 2018)

[2]. Harshal Patel, Brijesh mistry, A paper on footstep energy production, IJIRST International Journal for Innovative Research in Science \& Technology| Volume 4 | Issue 12 | May 2018, ISSN (online): 2349-6010

[3]. Marshiana. D, Elizabeth Sherine. M, Sunitha. N, Vinothkumar. Footstep Power production using Piezoelectric Sensors, Research Scholar, Department of EIE, Sathyabama University, Chennai, India,July-2016 ISSN 0974-3618

[4]. Kiran Boby, Aleena Paul K, Anumol.C.V, Josnie Ann Thomas, Nimisha K.KDept of EEE, MACE, Kothamangalam, Footstep Power Generation Using Piezo Electric transducer, International
Journal of Engineering and Innovative Technology (IJEIT)Volume 3, Issue 10, April 2014,ISSN:2277-3754

[5]. Electric power generation using piezoelectric crystal P.Balaji Naga Yashwanth, Gautham Kumar Moka, Donepudi Jashwanth. (Oct - 2009)

[6]. Richard, michael graham, (2006-08-04). "japan: producing electricity from train station ticket gates". Tree hugger. Discovery communications, llc.

[7]. IEEE standard on piezoelectricity, standards committee of the ieee ultrasonic's, Ferroelectrics and frequency control society, ansi/ieee std 1761987 (1988).

\section{Cite this article as :}

Akshaya Hatey, Vaibhavi Koli, Priti Mishra, Devanand Bathe, "Power Generation Using Piezoelectric Material ", International Journal of Scientific Research in Science and Technology (IJSRST), Online ISSN : 2395-602X, Print ISSN : 23956011, Volume 7 Issue 4, pp. 131-134, July-August 2020. Available at doi : https://doi.org/10.32628/IJSRST207436 Journal URL : http://ijsrst.com/IJSRST207436 